\title{
The Influence of Socio Cultural and Educational Background on EFL Learners' Motivation
}

\author{
Meta Keumala1, Nanda Marlina Abdul Samad2, Iskandar Abdul \\ Samad $^{3}$, Noor Rachmawaty 4 \\ ${ }^{1,3}$ Universitas Syiah Kuala, Indonesia \\ ${ }^{2}$ IAIN Zawiyah Cot Kala Langsa, Indonesia \\ ${ }^{4}$ Universitas Mulawarman, Indonesia
}

Abstract: It is undeniable that motivation plays a very important role in the learning process of students. However, some learners still face difficulties in learning English language due to some factors such as differences on its cultural aspects that contributes to the lack of intercultural competence on EFL learners. The aim of the research is to investigate the socio cultural and educational factors that influence the learner's motivation on English as Foreign Language (EFL) learning among post-graduate students of English Department of Syiah Kuala University, Aceh, Indonesia. The method applied was descriptive qualitative in which the data were collected through questionnaire administration. The results showed that sociocultural and educational background impacted positively on learners' motivation in EFL learning. Students who are in collectivistic culture $(60 \%)$ carried traditional thinking in facing new culture during the EFL learning process while the rest of the students who are in the part of individualistic culture (40\%) tend to react positively in facing new culture. Furthermore, educational background also has impacted the learners' motivation. Students' prior knowledge contributed to (70\%) their learning achievement

Keywords: English as a Foreign Language (EFL), Learners' Motivation, Socio Cultural Background, Educational Background

\section{INTRODUCTION}

The role of English language in Indonesia is still as a priority in the teaching of English as a Foreign Language (EFL). However, English, as the most important foreign language that is taught in schools, is not used in society. It is also not functioned as a tool of communication in the law court and the education system. Furthermore, it does not have any special status in the language legislation. As Crystal (2003) states that making easy generalizations about the social functions of English are not easy in a country like Indonesia where it is not the first language. In inner circle countries, English is used for all communicative purposes, but in Indonesia, its role is defined primarily by means of a conscious process of language planning, rather than by linguistic evolution.

Thus, it may contribute to learners' motivation as the most important point in the learning of EFL which then impacts to their learning achievement. Many researches have been carried out to promote this issue in order to increase 
students' motivation in EFL learning. In line with this, Dornyei (2001) states that motivation is something complicated that can only be recognized by one's efforts in acting so that it cannot be expressed by just one approach.

According to Brown (2000), motivation is classified into integrative and instrumental. Firstly, as explained by Gardner and Lambert (1959) as cited in Pourhosein Gilakjani, Leong, \& Saburi (2012), integrative motivation in language learning is usually aimed at self-improvement and increasing knowledge of foreign cultures. in other words, students learn the language so that it can be well received by other people who speak the target language. Meanwhile, instrumental motivation stems from the need to study L2 (second language) for functional or external reasons. For the sake of achieving certain goals, as well as functional goals such as having a learning target to learn to pass the exam and financial rewards.

Furthermore, Dörnyei (2001) states that intrinsic motivation refers to the motivation to engage in an activity because that activity is enjoyable to do. Extrinsic motivation refers to the actions that are performed to get some instrumental aims like reaching a reward or discontinuing a punishment. There is a close relationship between the two types of motivation. As explained by Brown (2000) that extrinsic motivation can be transformed into integrative motivation if there is influence from others so that students who study L2 for integrative purposes.

Moreover, as Brown (2001) states that intrinsic motivation can turn out to be integrative motivation if the L2 learner wants to integrate with the L2 culture; intrinsic motivation can also turn out to be instrumental motivation if the L2 learner wishes to gain aims using L2. Likewise, learners with the same integrative motivation can indicate great differences of intrinsic and extrinsic motivation. Intrinsic and extrinsic motivation is pertinent to integrative and instrumental motivation related to $\mathrm{L} 2$ language learning.

This study aims to investigate the impact of learners' sociocultural and educational background to their motivation in learning English as a Foreign Language (EFL). In order to define clearly about the variables, the researchers propose a research question: How far does sociocultural and educational background influence learners' motivation in EFL learning process? To answer the question the researchers then analyze the terms as follows:

In accordance with the previous background, a research question was formulated: To what extent does sociocultural and educational background influence learner's motivation in EFL learning?

\section{LITERATURE REVIEW}

\section{Social Identity and Socio Cultural Identity}

The reality found in various educational institutions clearly explains the situation in which socio-cultural and educational backgrounds have a very significant influence on students who are trying to study EFL because EFL students tend to have a lot of difficulties compared to native students. Terenzini et 
al (1993) states the influence of students transitioning into higher education as follows:

\begin{abstract}
"The transition from high school or work to college is an exceedingly intricate spectacle. The nature and subtleties of the process differ according to the students" social, family, and educational background; personality; educational and occupational orientations and aspirations; the nature and mission of the institutions being attended; the kinds of peers, faculty, and staff members encountered; the purpose and nature of those encounters; and the interactions of all these variables. The process is a highly interrelated, web-like series of family, interpersonal, academic, and organizational pulls and pushes that shape student learning and persistence." (p. 61)
\end{abstract}

According to Terenzini et al (1993), EFL learners are forced to adapt to new academic and social systems because these new academic and social systems are not part of their family and cultural traditions. Thus, adapting to new academic and social systems requires them to break away from their old traditions and cultural norms. As Engle (2007) states that learning L2 is a continuation of their academic and social experiences in high school.

Furthermore, as explained by Trice (2004) that knowledge of the diverse cultures that have been possessed by students since their children influences their academic success because they have a greater chance of exposure. In fact, minority communities often do not have adequate social assets, thus influencing the learning process because the linguistic and cultural competencies they have are so deep that it is rather difficult to develop social networks. More explicitly, Wells (2008) states that personal and social connections that are attempted by someone, are usually done at a young age and usually develop since school as an addition to their home environment.

According to Govea (2007), in comparing cultural background in education, it is divided into two types; namely collectivistic culture and individualistic culture. Collectivistic culture focuses on how the society reacts to the culture but they still think traditionally. On the contrary, the individualistic culture has more positive reactions on the new culture. It is described clearly in Table 1 below.

Table 1. Comparing Individualistic and Collectivistic Culture

\begin{tabular}{|c|c|}
\hline Collectivistic Culture & Individualistic Culture \\
\hline $\begin{array}{l}\text { The society shows a positive attitude towards } \\
\text { whatever is traditional. }\end{array}$ & $\begin{array}{l}\text { The society shows appositive attitude towards } \\
\text { whatever is new. }\end{array}$ \\
\hline Students are expected to learn how to do. & One is never too old to learn education. \\
\hline $\begin{array}{l}\text { The young have to learn while the old do not } \\
\text { accept the student role. }\end{array}$ & Students are expected to learn how to learn. \\
\hline $\begin{array}{l}\text { Individual students intervene in class only when } \\
\text { called upon personally by the teacher. }\end{array}$ & $\begin{array}{l}\text { Individual students speak up in class in } \\
\text { response of the general invitation by the } \\
\text { teacher. }\end{array}$ \\
\hline $\begin{array}{l}\text { Education is a way of gaining prestige in one's } \\
\text { environment. }\end{array}$ & $\begin{array}{l}\text { Education is a way of improving one's } \\
\text { economic worth and self respect based on } \\
\text { ability and confidence. }\end{array}$ \\
\hline
\end{tabular}


Acquiring diploma is more important than Acquiring is more important than diploma. acquiring competence.

Source: Govea (2007)

As a result, learners' socio cultural background contribute to the determination of the learners' success in learning EFL and impacts to their academic performance which then causes significant social, cultural, and academic success.

\section{Students’ Prior Knowledge}

Prior knowledge is knowledge that has been obtained by a student and becomes a capital for his steps in obtaining similar additional knowledge. As Robinson (1994) states that a large number of students claim to have good ideas but it is difficult to express them for fear of making mistakes. The main factor is the teaching and learning process which comes primarily from the teacher and students as the subject.

This gives the impression that EFL students need to exchange only socially and culturally with cultural boundaries when learning English. Li, Chen \& Danmu (2010) state that an academic culture alarm is directly related to the learning environment of an academic institution, including the education system, lecture style, assessment, the relationship between students, and lecturers. In addition, Li, Chen \& Danmu (2010) also states that international students from Asian countries, who only have learning experience with their country's education system, may feel a significant difference when they begin their studies in different languages.

\section{The Main Issue}

The lack of intercultural competence is one of the main problems that are faced by foreign language learners, it is often identified as the outcome of the radical differences present between the learners' culture and the target language culture; differences that may cause learners' disappointment. In the absence of intercultural competence and in an effort to maintain their psychological comfort, foreign language learners keep some distance and they even gradually develop a negative attitude which may impact their learning motivation. In relation to this issue, the researchers will describe the influence of socio cultural and educational background on learners' motivation in EFL specifically in Results and Discussions.

\section{RESEARCH METHOD}

The qualitative data were obtained from questionnaires. This study was carried out in the English Education Department of Syiah Kuala University. The questionnaires were administered to 20 students of Post Graduate of English Education Departments of Syiah Kuala University. Then, the data findings from the questionnaires were analyzed through the Likerts Scale to describe the percentage of students' motivation, the status of the foreign culture and educational background. 


\section{FINDINGS AND DISCUSSION}

The results from the distribution of questionnaire will be described clearly in this part. The researcher divides the result and discussion sections into three parts: learners' motivation, socio cultural background; and educational background. To begin with, the learners' motivation in learning EFL is shown in the following figure.

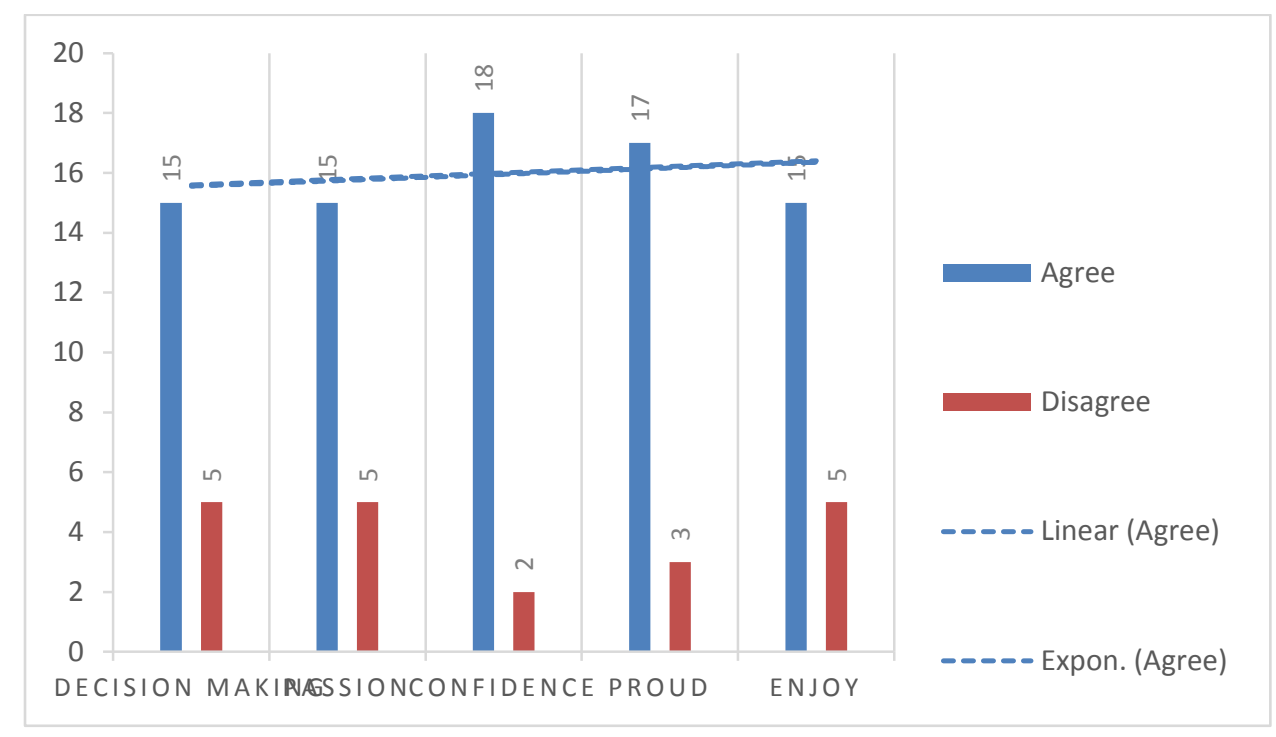

Figure 1. Intrinsic Motivation

Intrinsically, fifteen students decided to enroll English department major based on their own decisions. The other fifteen students enrolled this department because of their passion in learning EFL. Based on that figure, it was also reported that there were 18 students who more confident after learning EFL. They enjoyed and felt happy during their FL learning. Meanwhile, 17 students were proud of being English students and the other 15 enjoyed the language learning.

In line with this, Dörnyei (2001) states that since the late 1990s, researchers have examined that motivation to learn languages in a more processoriented manner, realizing the diversity of student characters, the relation between characters in themselves, opportunity time, is strongly influenced by contextual factors, both internal and external for each individual. In this case, it can be seen clearly that motivation becomes one of the internal factors encouraging students to learn English.

Apart from the intrinsic motivation, parents are also considered having an influence on students' decisions in EFL learning. To make it clearer, the data are firstly described in Figure 2 as follows: 


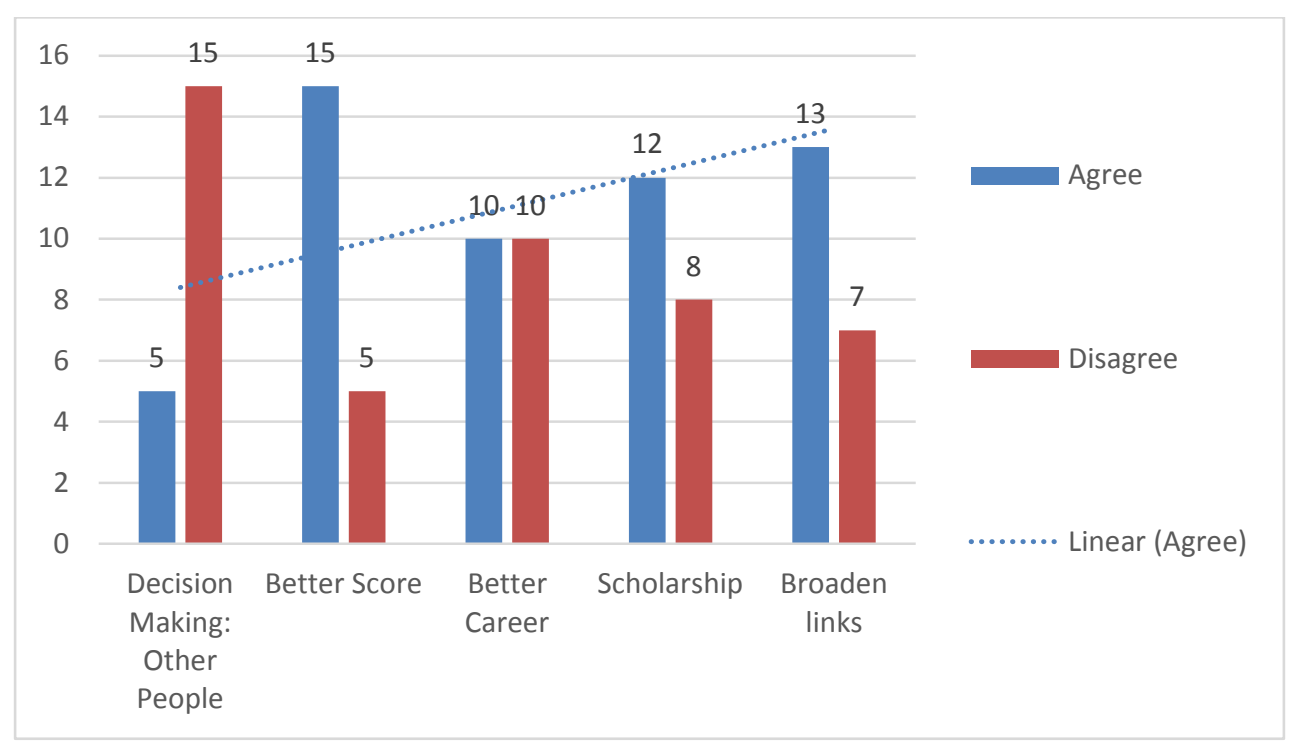

Figure 2. Extrinsic Motivation

Figure 2 shows the reverse data on students' motivation from the intrinsic factor. The trend shows that 15 students decided to take English Department in order to get better score while 13 of them would like to broaden their connection and links. In addition, 12 students are targeting scholarship, 10 students' aim to have better career. Only 5 of them who decided to take English department because of somebody else.

Most students feel that their desire to learn FL is generally affected by their intrinsic motivation as well as some other external factors. Highly motivated students fulfill their passion in learning the target language and are happy, proud, confident and optimistic to achieve better future. Besides, motivation also impacts on students' learning attitudes. These attitudes are more concerned with what learning situation they are in and how the factors of teachers, instructions, curriculum, lesson plans, and evaluation process affect their learning.

According to Ryan and Deci (2000), intrinsic or extrinsic motivation is a unitary series that describes the process of changing motivation. However, they believe that human motivation does not need to be developed through each stage as an orderly sequence because it may be walking back and forth between each orientation. For example, when someone does an activity because of a gift (external factor); however, during the process, the person may feel that he has done it well and this gradually arouses his / her intrinsic motivation. Furthermore, Noel et al (2013) states that a person may have more than one orientation (goal) to learn a second / foreign language at the same time, although some people feel learning it is far more important than others. Furthermore, the next variable is the socio cultural influences on students' motivation in EFL learning where it is compared between two items; collectivistic culture and individualistic culture. Figure 3 shows specific data about this variable. 


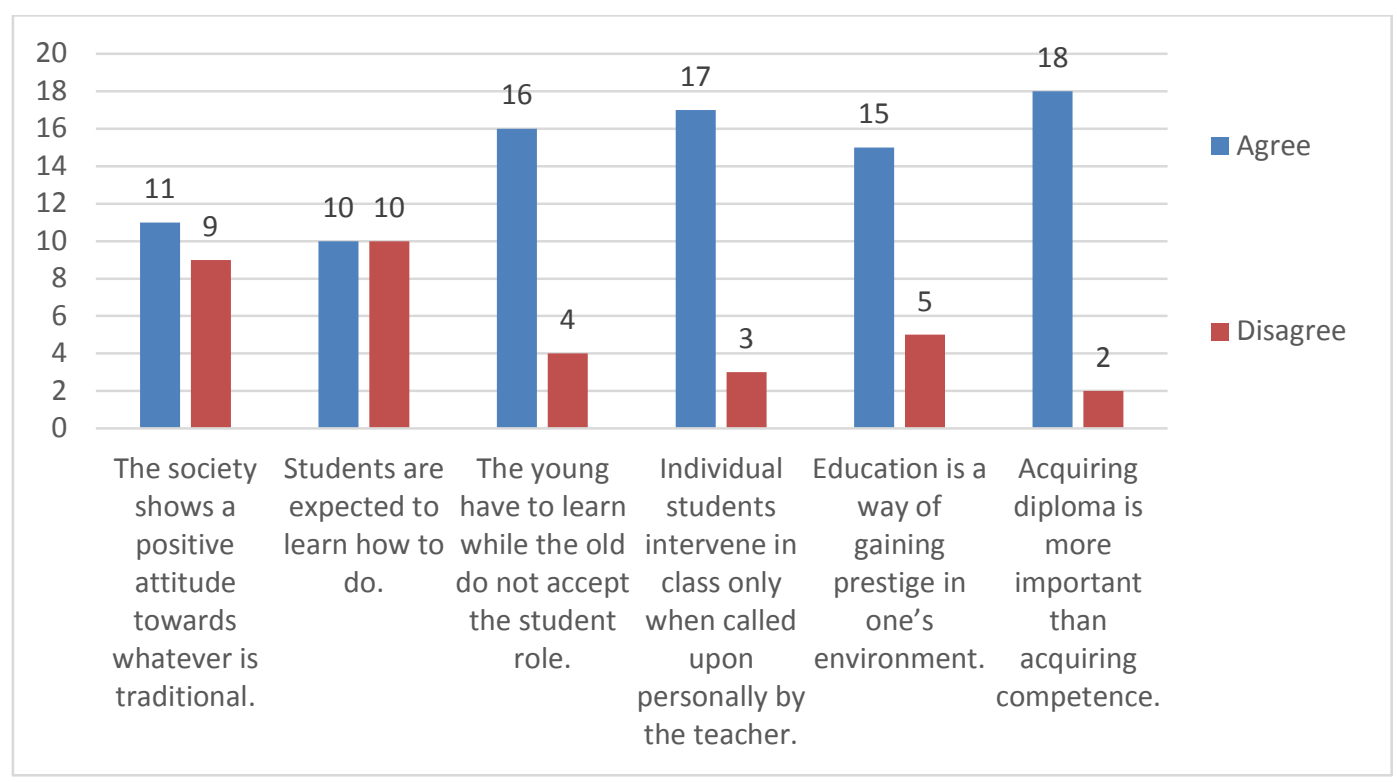

Figure 3. Collectivistic Culture Vs. Individualistic Culture on Education

The above figure shows that 18 students answered that their society where they live and grow up think that acquiring diploma is more important than acquiring competence. For some people in some regions in Aceh, education is a way of gaining prestige in one's environment as can be seen in the figure above those 15 students answered so. Practically, in the process of teaching and learning of EFL, students' opportunities to be actively participated in the learning processes are still low. It can be seen in the figure that 17 students agreed on this statement. In fact, most of the students wait until they are invited to react to teachers' explanation. It is because the society considers that interrupting older people is rather impolite attitude.

In addition to this topic, 16 students agree that the society asks young people to learn while the old do not accept the student role. 10 students agree that they are expected to learn how to do. It is clear that the society forces younger ones to do what the older wants. In this collectivistic culture, the society rather accepts positive attitude towards traditional things. There are 11 students answered so, which means that the society may hardly respond positively towards something new.

EFL learners are exposed to a new culture through its food, beliefs, ways of life, and societal norms. The learner unconsciously becomes a part of it, and put on a space of acculturation. According to Kramsh (1991), the nature of culture and language are inseparable as a universe or closely related experience. He also added that students who have a cultural awareness of the target language in the process of learning a language can help accelerate their mastery of the target language. In his view, students who study L2 or EFL must learn the culture of the target language because language cannot be learned without understanding the cultural context in which it is used.

To sum up, the students' answers show that their socio cultural background is more likely to be collectivistic rather than individualistic. According to Rezig (2015), there is a general agreement that a strong cultural 
understanding and the ability to reflect it in language communication, comprehension and production are essentials for reaching professional levels of language performance. In line with this idea, Triandis (1997) states that human beings are ethnocentric which reflects the truth that we all grow in a specific culture and learn to believe that the standards, principles, perspectives, that we acquire from our culture are the way we look at the world. It is obviously seen that the Acehnese culture, as the original tribe of the respondents, is still carrying out traditional thinking in parenting which also impacts to the attitude of the nonnative English teachers.

Moreover, the last variable that becomes the main issue in this study is students' educational background. Teachers' main concern in the process of teaching and learning is to transfer their ideas to the students as clearly, understandably, and efficiently as possible. This leads to be the constituent factor of EFL learners' prior knowledge. Along with this idea, parenting style also determines how students get their prior knowledge. As defined by Rezig (2015) that many studies brought evidence that the learning process begins from the learner's prior knowledge, then through the treatment of the new information presented.

In addition, Ferdoes (2016) states that difficulties faced by different L2 language learners may arise from factors such as L1 transfer, the orthography of L1 writing, religious conformity, cultural resistance to self-expression, parental involvement, fulfillment of teacher expectation based on stereotyping, and the route learning background that is embedded in own culture . In this case, figure 4 shows the respondents' reaction on this variable.

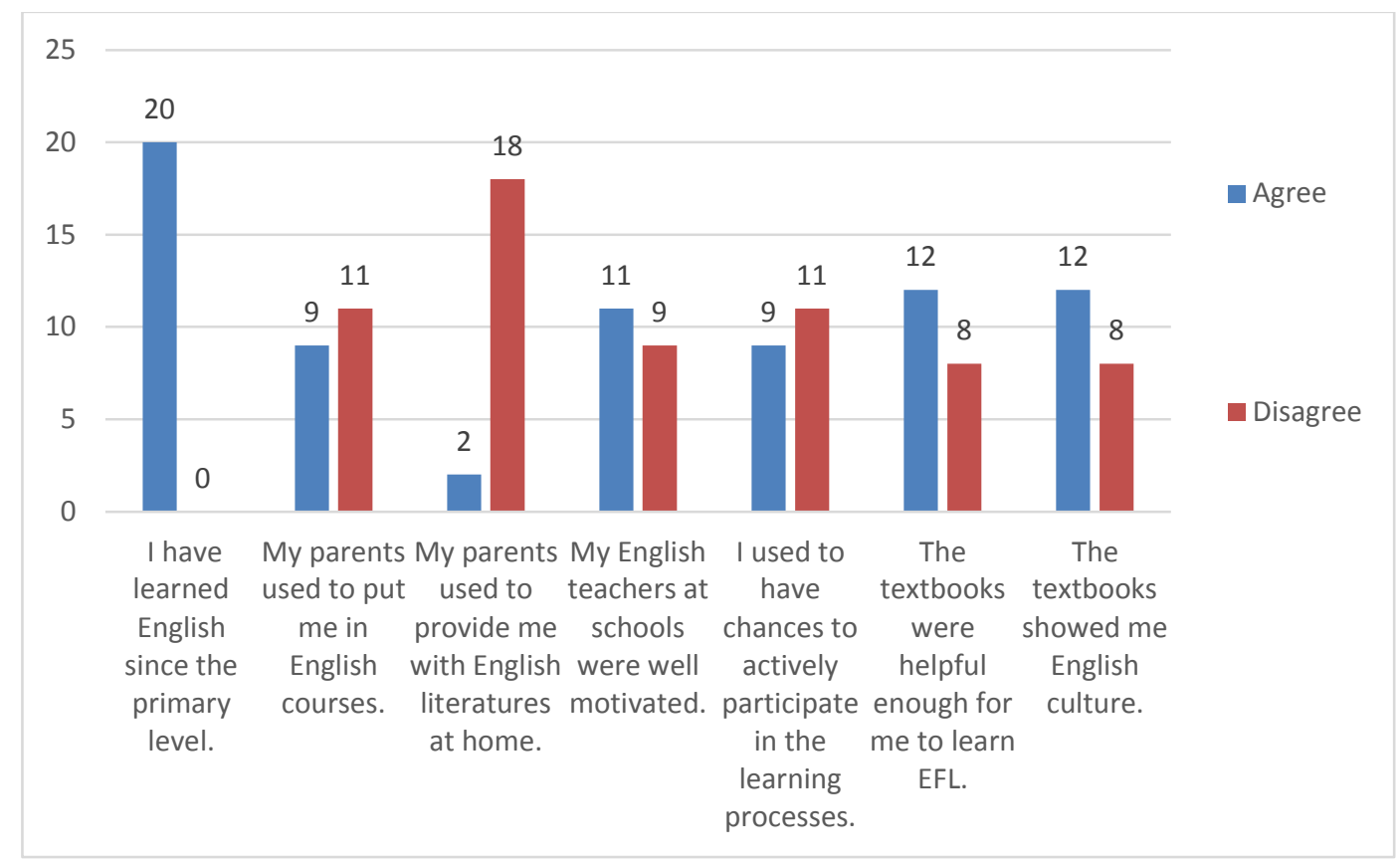

Figure 4. Educational Background

As can be seen from Figure 4 above, the respondents have been studying EFL since primary level of education. However, there are only few of them who used to be given extra access to learn EFL deeper through the courses or the 
literatures beside school lessons. In line with this idea, Ferdous (2015) notes in her research:

\begin{abstract}
"The first answer gave out several ratio of educational status for the fathers of the Bengali medium schools students, whereas the fathers of the English medium schools students stood as only postgraduate and graduate ratio. This difference in educational status takes significant toll on their children's' academic involvement by the parents. De Broucker and Underwood point out that those parents with high education provide the most conductive environment for their children to study, thus providing the necessary motivation for them to proceed to higher education (Ekber \& Polat, 2013 as cited in Ferdoes, 2016, p. 50).”
\end{abstract}

The other elements of the factors of students' prior knowledge are the role of teachers, and textbooks. Figure 4 shows that 11 from 20 respondents answered that their teachers were well-motivated and 9 respondents responded that they were given chance to actively participate in the process of teaching and learning. Moreover, Andrade (2006) states that Asian international students face real challenges when they enter academic goals that differ from their original culture including in terms of classroom participation, critical thinking skills, informal procedures in classrooms, attendance requirements, honesty and independent learning. In addition, the use of appropriate and good textbooks is also a factor of student motivation. Brown (2001) states that the problem that arises in the assessment of international students is when the assessment is done, the way international students react and or respond to judgments they receive is often considered unpredictable or even incompatible with the norms prevailing in the area.

\title{
CONCLUSION
}

This study finds out that students' socio cultural and educational background contributes to their motivation in EFL learning. Most respondents were found to be highly motivated in learning FL. They are more likely to be intrinsically motivated as can be seen from their response of questionnaire. In contrast, they also have external factors to decide English Department as their major faculty. The students' answers also show that their socio cultural background is more likely to be collectivistic rather than individualistic. It is suggested that the educational institutions do revisions on its curriculum and instruction which are applicable to less motivated learners since the provision of instruction, guidance and suitable curriculum leads to better achievement of EFL students in learning English.

\section{ACKNOWLEDGMENT}

The researchers would like to thank all participants who have contributed sincerely by giving responses until the completion of this research article. 


\section{REFERENCES}

Andrade, M. S. (2006). International students in English-speaking universities: Adjustment factors. Journal of Research in International Education, 5(2), $131-154$

Brown, H. D. (2001). Teaching by Principle and Interactive Approach to Language Pedagogy. New York: Longman Inc.

Creswell, J. W. (2009). Research Design: Qualitative, Quantitative, and Mixed Methods Approaches (3rd ed.). The USA: Sage

Crystal, D. (2003). English as a Global Language. Cambridge: Cambridge University Press.

Dornyei, Z. (2001). Motivational Strategies in the Language Classroom. Cambridge: Cambridge University Press.

Engle, J. (2007). Postsecondary Access and Success For First-Generation College students. American Academic, 3(1), 25-48

Ferdoes, F. (2016). Influence of students' socio cultural and educational background on English language learning (Doctoral dissertation, BRAC University).

Govea, J. M. (2007). The Cultural Influence of 'Power Distance'in Language Learning. The University of Birmingham, UK. Retrieved August, 31, 2015 .

Kramsch, C. (1991). Culture in language learning: A view from the United States. Foreign language research in cross-cultural perspective, 217-240.

Li, G., Chen, W., \& Duanmu, J. L. (2010). Determinants of international students' academic performance: A comparison between Chinese and other international students. Journal of Studies in International Education, 14(4), 389-405.

Noel, A., Stark, P., \& Redford, J. (2013). Parent and Family Involvement in Education, from the National Household Education Surveys Program of 2012. First Look. NCES 2013-028. National Center for education statistics.

Gilakjani, A. P., Lai-Mei, L., \& Sabouri, N. B. (2012). A study on the role of motivation in foreign language learning and teaching. International Journal of Modern Education and Computer Science, 4(7), 9.

Rezig, N. (2015). The Learners' Educational and Cultural Background Effect on Their Proficiency in Learning English the Case of First Year English Students at Biskra University. Thesis. Biskra University.

Robinson, P. (1994). Implicit knowledge, second language learning, and syllabus construction. Journal of Professional Nursing, 10(1), 161. 
Ryan, R. M., \& Deci, E. L. (2000). Self-determination theory and the facilitation of intrinsic motivation, social development, and well-being. American Psychologist, 55(1), 68.

Terenzini, P. T., Rendon, L. I, Upcraft, M. L., Miller, S. B, Allison, K. W., Gregg, O.L, \& Jalomo, R. (1993). The transition to college: Diverse students, diverse stories. Research in Higher Education, 35(1), 57-73.

Triandis, H. C. (2007). Culture and psychology: A history of the study of their relationship. Guilford Press.

Trice, A. G. (2004). Mixing it up: International graduate students' social interactions with American students. Journal of College Student Development, 45(6), 671-687. 